\title{
Polyvinyl Alcohol/Polyaniline/ZnO Nanocomposite: Synthesis, Characterization and Bactericidal Property
}

\author{
Alireza Samzadeh-Kermani*, Mohsen Mirzaee, Mansour Ghaffari-Moghaddam \\ Department of Chemistry, Faculty of Science, University of Zabol, Zabol, Iran \\ Email: :arsamzadeh@yahoo.com
}

Received 3 November 2015; accepted 31 January 2016; published 3 February 2016

Copyright $@ 2016$ by authors and Scientific Research Publishing Inc.

This work is licensed under the Creative Commons Attribution International License (CC BY).

http://creativecommons.org/licenses/by/4.0/

(c) (i) Open Access

\section{Abstract}

In this study, a new nanocomposite based on Polyvinylalcohol/Polyaniline/Zinc oxide (PVA/PANi/ $\mathrm{ZnO}$ ) was successfully synthesized. ZnO powder was used to produce its nanoparticles (NPs) using conventional method. PVA/PANi composite was used to produce ZnO NPs. Polyaniline was synthesized in sol solution of PVA in the presence of ammonium persulphate. Morphology and the size of ZnO NPs in nanocomposites were studied via Scanning Electron Microscopy (SEM), X-ray Diffraction (XRD) analysis and Infrared (IR) spectroscopy. According to XRD results, the average size of prepared ZnO NPs was found to be at the range $22-34 \mathrm{~nm}$. SEM images were shown hexagonal shape for ZnO NPs, which was used for the investigation of antibacterial property. Finally, the antibacterial activity of the prepared ZnO NPs and nanocomposites was evaluated against two bacteria of Gram positive Staphylococcus aureus and Gram negative Escherichia coli using paper disc diffusion method. The results were shown that the prepared nanocomposites were effective against two bacteria.

\section{Keywords}

Nanostructure, Polymers, Electron Microscopy (SEM), Infrared Spectroscopy, Antibacterial

\section{Introduction}

Nanotechnology is fundamentally about preparation of nanoscale materials [1]. NPs are subjected in an increased interest, because they combine the features of polymers with a small quantity of nanoparticles (less than $5 \%$ by weight) [2]. Recently, all researches about NPs have gained considerable importance in the areas of bi-

"Corresponding author.

How to cite this paper: Samzadeh-Kermani, A., Mirzaee, M. and Ghaffari-Moghaddam, M. (2016) Polyvinyl Alcohol/ Polyaniline/ZnO Nanocomposite: Synthesis, Characterization and Bactericidal Property. Advances in Biological Chemistry, 6, 1-11. http://dx.doi.org/10.4236/abc.2016.61001 
ology, medicine, and electronics because of their unique particle size and shape dependent physical, chemical and biological properties [3] [4]. $\mathrm{ZnO}$ is a wide band gap (3.37 eV) II-VI compound semiconductor which has received a lot of attentions over the last decade because, it has a wide range of useful properties including electrical [5], optical [6], chemical [7] and magnetic [8]. Therefore, $\mathrm{ZnO}$ has become extraordinarily important because of its wide applications such as in catalysis [9], gas sensing [10], semiconductors [11], piezoelectric devices [12], UV-shielding materials [13], polymer coating [14], photochemical [15] and antibacterial agents [16]. As $\mathrm{ZnO}$ is a multifunctional material, the study on its NPs has been focused on their preparation using various methods including solid state reaction [9], flame spray pyrolysis [17], microwave-assisted method [18], sonochemical route [19], sol-gel [20], hydrothermal [21] and mechanochemical methods [22]. ZnO powder inhibits the growth of gram-positive bacteria more strongly than gram-negative bacteria [23]. This research was focused on metal oxides like $\mathrm{ZnO}$ as antibacterial agents to prevent bacterial growth. Recently, there have been several reports regarding the antimicrobial activity of ZnO NPs [24]. ZnO displays many interesting properties at nanoscale, and has significant applications as antibacterial and antifungal agents. It also holds importance in biomedical sciences [25]. ZnO has shown a considerable antibacterial activity at $\mathrm{pH}$ values at the range 7 - 8 without the presence of light [26]. Polyvinyl alcohol (PVA) is an important water-soluble transparent polymer, and is extensively used in industries due to the excellent chemical and physical properties, non-toxicity, good chemical resistance, good film formation capacity, biodegradability and high crystal modulus. PVA is used here in hydrolyzed form with the degree of $85 \%$ hydrolysis [27]. It is a polymer with many technological, pharmaceutical and biomedical applications [28]. It can be used for coating of $\mathrm{ZnO}$ [29], titanium dioxide [30] and Ag [31]. PANi, an intrinsically conducting polymer, has received great attentions because of its wide potential formany technological applications, such as sensors, anticorrosion coatings, electro rheological fluids [32] and good environmental stability [33]. PANi is usually obtained as powder via precipitation polymerization [34].

\section{Materials and Methods}

\subsection{Materials}

All reagents in this work were of analytical grade and purchased from Merck (Darmstadt, Germany). Zinc oxide as a precursor for the preparation of ZnO NPs, polyvinyl alcohol as a matrix for stabilization of NPs and pure aniline as a starting material for synthesis of PANi, were used.

\subsection{Microorganisms}

The antibacterial activity of prepared ZnO NPs and nanocomposites was carried out using two different bacterial strains including gram positive Staphylococcus aureus (Staph.) and gram negative Escherichia coli (E. coli). All bacterial strains were provided from the Faculty of Pharmacy, Zabol University of Medical Sciences, Zabol, Iran.

\subsection{Preparation of ZnO Nanoparticles}

First, ZnO powder ( 0.1 - $1 \mathrm{~g}$ ) was dissolved in $100 \mathrm{ml}$ of $1 \%$ acetic acid and the solution was sonicated for 30 minutes in orther to obtain $\mathrm{Zn}^{2+}$ cations. Then, $50 \mathrm{ml}$ of $1 \mathrm{M} \mathrm{NaOH}$ was added dropwise together with magnetic stirring until the solution attained $\mathrm{pH} 10$. The solution was heated in water bath at $\left(40^{\circ} \mathrm{C}-80^{\circ} \mathrm{C}\right)$ for about 3 hours. It was filtered and washed with distilled water three times, and then dried in an oven at $50^{\circ} \mathrm{C}$ for 1 hour according to the conventional procedure [35].

\subsection{Preparation of Aniline Hydrochloride}

Aniline hydrochloride was prepared by the reaction of pure aniline with concentrated hydrochloric acid via mixing at the ratio of 1:2 [36]. First, $20 \mathrm{ml}$ of hot aniline was added dropwise to $40 \mathrm{ml}$ of hydrochloric acid, and the mixture stirred consequently using magnetic stirrer. The mixture color was changed from colorless to violet, then cooled at room temperature. The mixture was filtered and washed with concentrated hydrochloric acid. Finally, the obtained white sediment was dried at $40^{\circ} \mathrm{C}-50^{\circ} \mathrm{C}$ in an electrical oven.

\subsection{Preparation of PVA/PANi/ZnO Nanocomposites}

PVA/PANi/ZnO nanocomposites were synthesized via an in situ chemical polymerization of aniline hydrochlo- 
ride into the suspensions containing PVA and different concentrations of ZnO NPs. In a typical synthesis, a suspension was prepared by dissolving $6.5 \mathrm{~g}$ PVA in $100 \mathrm{ml} 0.1 \mathrm{M} \mathrm{HCl}$. The mixture was heated to attain a transparent solution, and then cooled at room temperature for half an hour. Different amounts of ZnO NPs were added to the mixture and then, $1.3 \mathrm{~g}$ aniline hydrochloride added slowly to every mixture and stirred at $-5^{\circ} \mathrm{C}$ for 30 minutes. $10 \mathrm{ml}$ of aqueous solution of ammonium persulphate $\left[\left(\mathrm{NH}_{4}\right)_{2} \mathrm{~S}_{2} \mathrm{O}_{8}\right] 0.1 \mathrm{M}$ was added to the mixture and allowed to complete the reaction for 12 hours under constant stirring at $-3^{\circ} \mathrm{C}$. Finally, the blue green mixture was prepared, and then dried at $40^{\circ} \mathrm{C}$ for $48 \mathrm{~h}$.

\subsection{Characterization}

\subsubsection{FT-IR Spectroscopy}

The prepared ZnO NPs and nanocomposites were analyzed using a Fourier transform infrared (FT-IR) spectrometer (Bruker Optics Ft Tensor 27, Germany).

\subsubsection{X-Ray Diffraction (XRD) Analysis}

The structure of PVA/PANi/ZnO nanocomposites was determined by X-ray diffraction using the Bruker-D8 Advanced (Germany) instrument. A wavelength $(\lambda) 0.15418 \mathrm{~nm}$ was used for these analyses. The XRD patterns were recorded at the scan speed of $2^{\circ} \mathrm{min}^{-1}$.

\subsubsection{Field Emission Scanning Electron Microscopy (FESEM)}

FESEM was applied to observe the surface morphology of PVA/PANi/ZnO nanocomposites using a Hitachi S4160 instrument. Thin films of the samples were prepared on graphite adhesives, and then the surface of samples was coated by gold powder using sputter hummer instrument.

\subsection{Antibacterial Activity}

The antibacterial activity of ZnO NPs was investigated against Staphylococcus aureus (Staph.) and Escherichia coli (E. coli) microorganisms by disk diffusion method in accordance with the procedure described by Hwang and Ma [37]. This method is a mean of measuring the effects of an antimicrobial agent on bacteria growth in a culture. Muller-Hinton Agar (MHA) powder was used as a culture medium for bacteria growth. To prepare the culture medium, $19 \mathrm{~g}$ of agar was dissolved into $500 \mathrm{ml}$ of distilled water, and then a transparent brown solvent was achieved via boiling the solution. MHA medium $(15 \mathrm{ml})$ was sterilized at $120^{\circ} \mathrm{C}$ for about 1 hour in autoclave, cooled to room temperature and then poured into sterilized petri dishes $(10-90 \mathrm{~mm})$. After cooling over 24 hours, the bacteria are swabbed uniformly across the culture plate. Filter-paper disks were placed on the surface of agar. To evaluate the antibacterial activity, $40 \mu \mathrm{l}$ of each of the samples was dropped moderately on disks' surface using a sampler. If the samples are effective against the bacteria at a certain concentration, then no colonies would grow and the concentration in agar is greater than or equal to the effective concentration. This region is called inhibition zone. The size of inhibition zone measures the efficacy of sample. A more effective sample produces a larger clear area around the disk. All tests were done under laminar flow hood. Finally, all petri dishes containing bacteria and antibacterial reagents were incubated at $37^{\circ} \mathrm{C}$ for $24 \mathrm{~h}$. At the end of incubation period, the diameters of inhibition zones formed around disks, were determined and presented in $\mathrm{mm}$. The results concerning antibacterial activity were expressed as strong activity (>13 mm), moderate activity (6 - 12 $\mathrm{mm}$ ), weak activity $(5 \mathrm{~mm}$ ) or no activity (inhibition zone $<5 \mathrm{~mm}$ ).

\section{Results and Discussion}

\subsection{FT-IR Spectroscopy}

FT-IR spectra of prepared ZnO NPs and nanocomposites were recorded and some partial changes in the absorption peaks of different concentration of nanocomposites C1, C2, C3 and C4 were observed (Figure 1). The broad band near $3429 \mathrm{~cm}^{-1}$ represents the hydrogen bonded O-H stretching vibration [38]. The band $2987 \mathrm{~cm}^{-1}$ represents asymmetric $\mathrm{C}_{\mathrm{sp}}^{3}-\mathrm{H}$ stretching frequencies of alkyl groups. The band at $448-550 \mathrm{~cm}^{-1}$ was pointed out $\mathrm{Zn}-\mathrm{O}$ stretching frequency [39]. The free $\mathrm{OH}$ functional group have a broad peak at $3600-3650 \mathrm{~cm}^{-1}$, and this peak goes toward $3100-3500 \mathrm{~cm}^{-1}$, if the OH group engaged in formation of hydrogen bond or complex with metal particles, so the broad peak of hydroxyl groups were appeared for nanocomposites in this range. The 


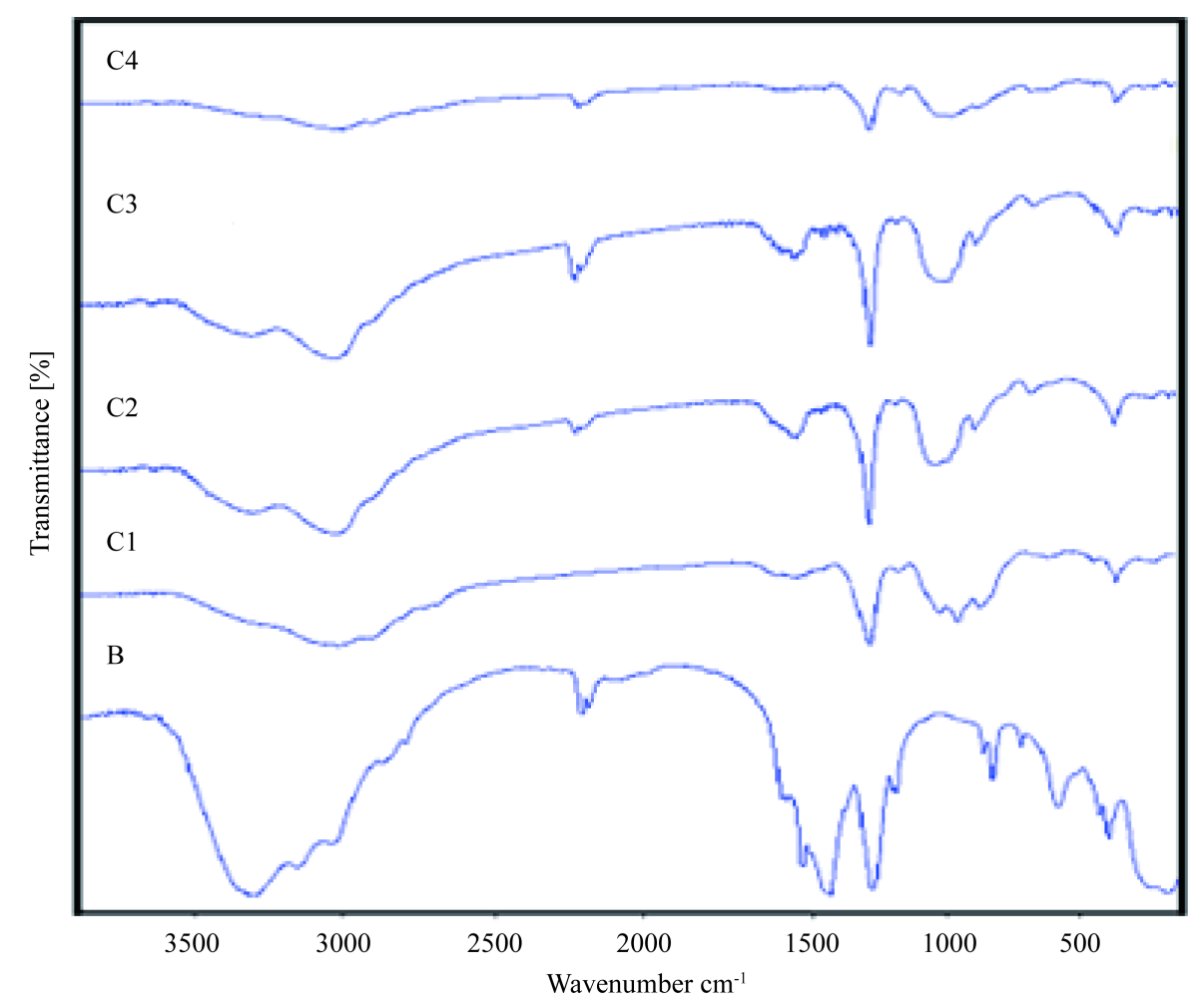

Figure 1. FT-IR spectra of prepared ZnO NPs (B), nanocomposites 1\% (C1), 1.5\% (C2), 2\% (C3) and $2.5 \%$ (C4).

presence of $\mathrm{C}-\mathrm{H}$ and $\mathrm{CH}_{2}$ bonds of Alkanes in the PVA structure, were confirmed with the stretching peaks around $2855-3000 \mathrm{~cm}^{-1}$ and bending at $1403 \mathrm{~cm}^{-1}$. A single medium peak in $3100-3500 \mathrm{~cm}^{-1}$ for aromatic $\mathrm{C}-\mathrm{H}$ and an intense peak in $1100-1350 \mathrm{~cm}^{-1}$ for C-N bond were shown for PANi. The presence of benzene rings in polyaniline structure was also confirmed with an intense C-H out of plane bending peak around 1475 $1600 \mathrm{~cm}^{-1}$.

\subsection{XRD Analysis}

The sharp and intense peaks around $2 \theta$ values of 31.8, 34.4, 36.2, 47.5, 56.6, 62.8, 67.90 and 68.5 with 100, 002, 101, 102, 110, 103, 112 and 201 diffractions, were related to ZnO crystalline hexagonal structure which formed benign stabilizing complex by polymeric matrix. All the diffraction peaks are in good agreement with those of hexagonal wurtzite structure of prepared $\mathrm{ZnO}$ nanoparticles [40]. The XRD patterns were clearly exhibited the presence of $\mathrm{ZnO}$ NPs in nanocomposites (Figure 2). The average particle size of every PVA/PANi/ZnO nanocomposite was obtained using Scherrer's Equation:

$$
D=\frac{K \lambda}{\beta \cos \theta}
$$

In which, $D$ is the crystallite size, $k$ is the shape factor that assumes a value of 0.89 for $\mathrm{ZnO}, \lambda$ is the $\mathrm{X}$-ray wavelength $\left(1.5418 \mathrm{~A}^{\circ}\right), \beta$ is the half height width of XRD peak and $\theta$ is the diffraction angle [16]. The diameters of $\mathrm{ZnO}$ nanoparticles were estimated to be at the range 22.57 - $33.90 \mathrm{~nm}$ for all samples.

$\mathrm{X}$-ray diffraction histograms for the size distribution of $\mathrm{ZnO}$ NPs were demonstrated that their concentration increment in nanocomposites, would cause a scale down in smaller sizes of $\mathrm{ZnO}$ NPs. This is due to the agglomeration of ZnO NPs with increasing their concentrations (Figure 3).

\subsection{FESEM Analysis}

SEM images of pure and coated ZnO NPs were shown in Figure 4. The images were shown that, uncoated ZnO 


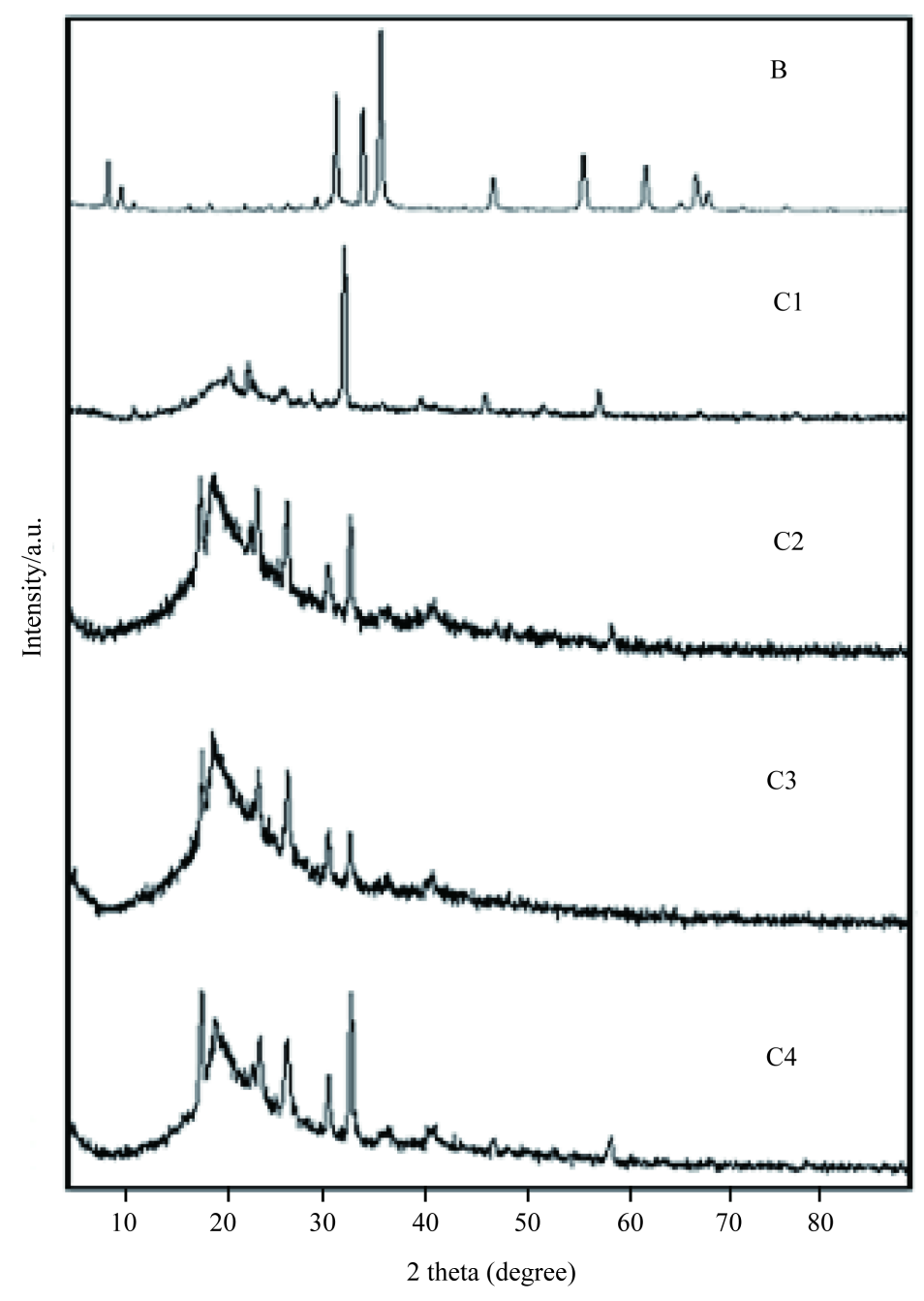

Figure 2. XRD spectra of prepared ZnO NPs (B) and nanocomposites $1 \%$ (C1), $1.5 \%$ (C2), $2 \%(\mathrm{C} 3)$ and $2.5 \%(\mathrm{C} 4)$.

NPs were aggregated and compressed, while coated NPs had a better distribution and homogeneity. SEM images were also shown that, samples with medium concentraction (like C2 and C3) had a better distribution. This is due to the less agglomeration of NPs in medium concentraction of samples. This fact confirms the results of XRD analysis.

\subsection{Antibacterial Properties of Prepared PVA/PANi/ZnO Nanocomposites}

The results of antibacterial activity of ZnO NPs and nanocomposites against bacteria were depicted in Table 1. It was shown that the inhibition zone increased with increasing ZnO NPs' content of nanocomposites, and also observed that the inhibition zone for Staph. was greater than that for E. coli. However, antibacterial activity could be attributed to antibacterial effect of ZnO NPs. It was suggested that ZnO NPs may affect the membrane of bacteria and inhibit their growth [41]. Antimicrobial activity of nanocomposites for low and high concentrations of ZnO NPs was low. This is due to the presence of small amounts of ZnO NPs in low concentration nanocomposite (C1), and agglomeration of ZnO NPs in high concentration nanocomposite (C4). At this circumstance the amount of interaction with cell membrane was decreased which would caused a reduction in the inhibition zone. In this test the antibacterial activity against Staph. was stronger than E. coli (Figure 5). Figure 6 was illustrated the scatter plot of the inhibition zone values for $\mathrm{ZnO}$ NPs and various concentrations of nanocomposites 1\% (C1), 1.5\% (C2), 2\% (C3) and 2.5\% (C4). 

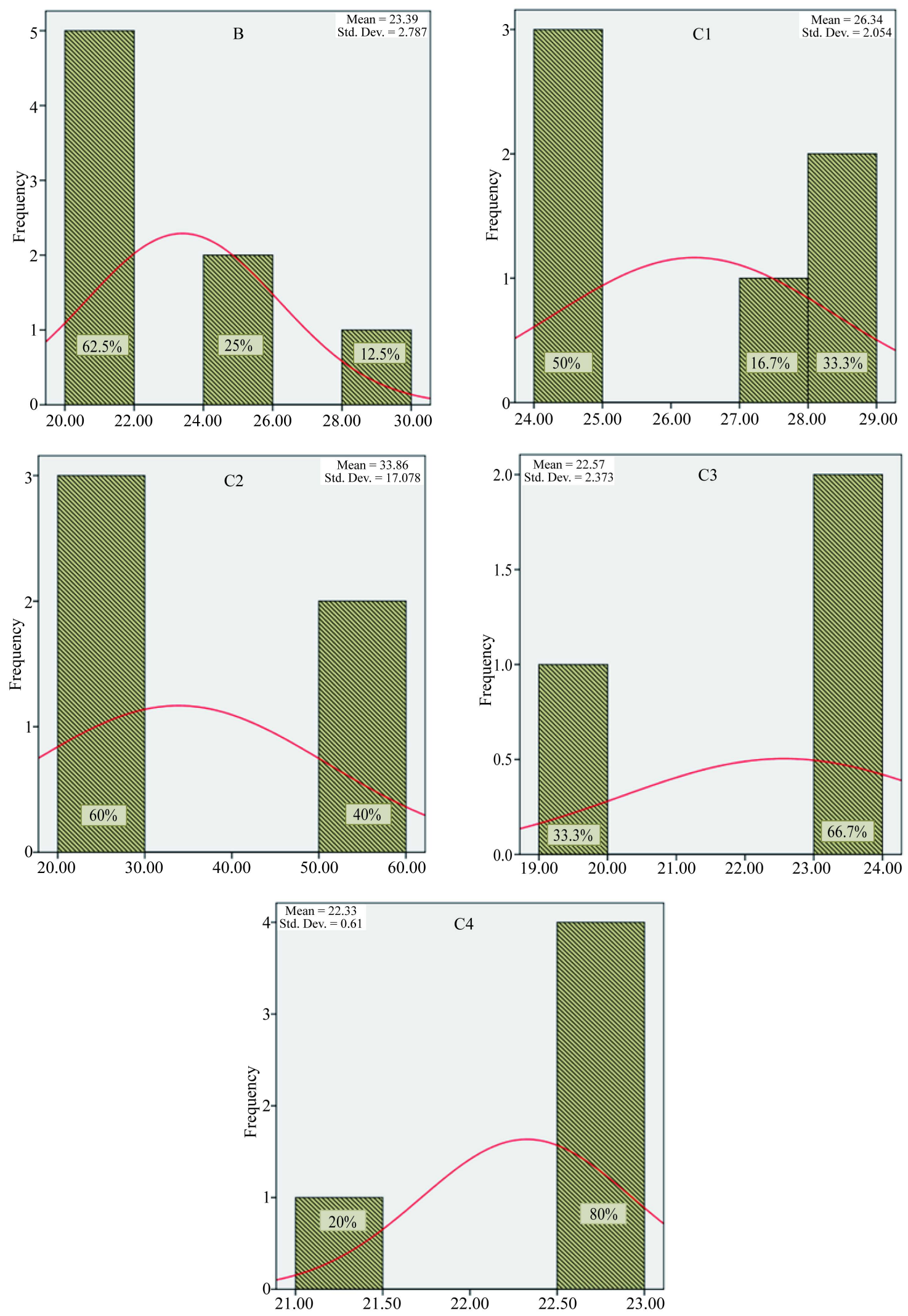

Figure 3. XRD histograms for the size distribution of $\mathrm{ZnO}$ nanoparticles (B) and different nanocomposites containing $\mathrm{ZnO}$ nanoparticles 1\% (C1); 1.5\% (C2); 2\% (C3); 2.5\% (C4). 

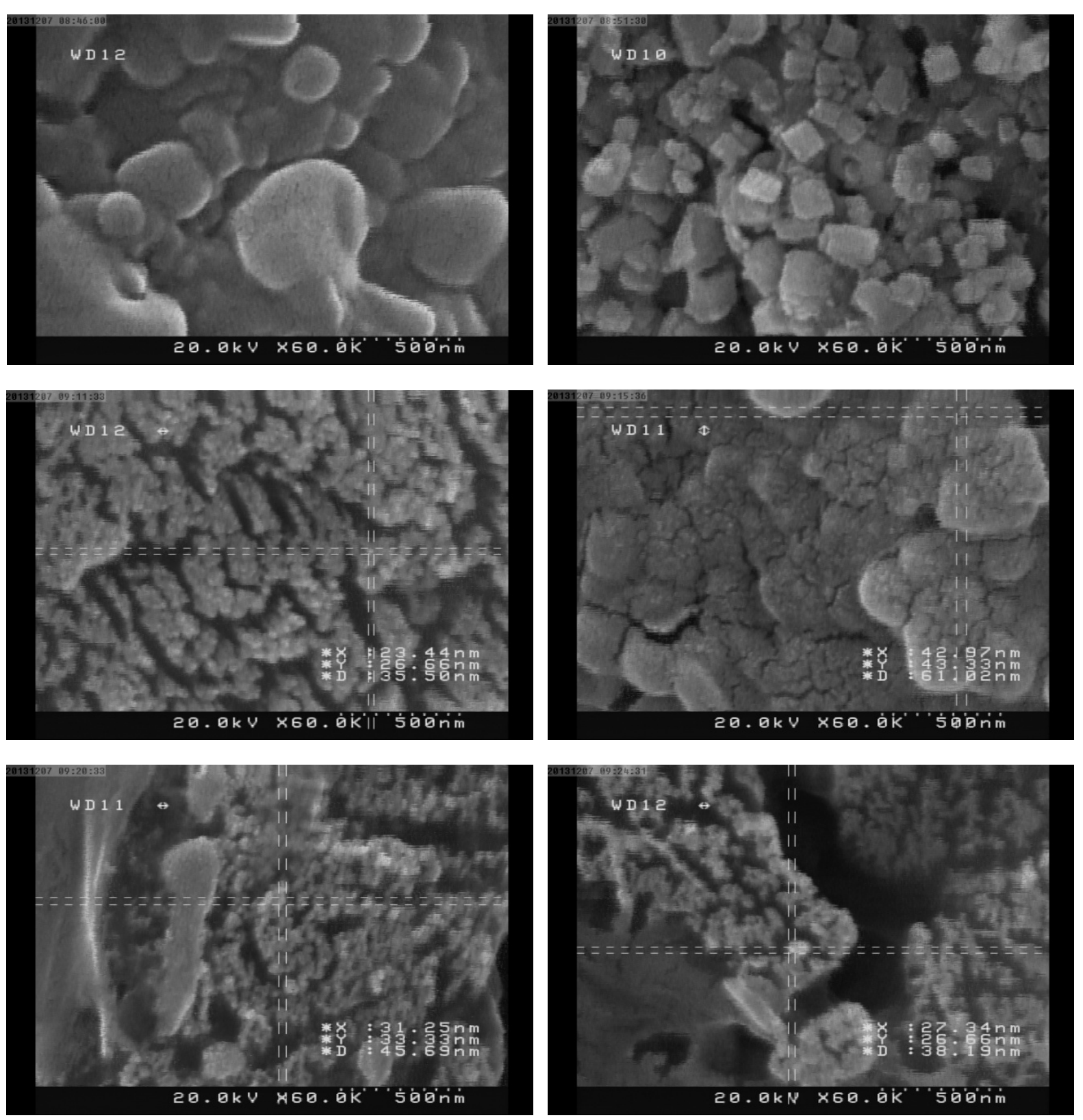

Figure 4. SEM images of PVA/PANi (A), ZnO NPs (B), nanocomposites 1\% (C1), 1.5\% (C2), 2\% (C3) and 2.5\% (C4).

Table 1. Average inhibition zone and standard deviation for ZnO NPs and various concentrations of nanocomposites $1 \%$ (C1), $1.5 \%$ (C2), $2 \%(\mathrm{C} 3)$ and $2.5 \%(\mathrm{C} 4)$.

\begin{tabular}{ccc}
\hline & \multicolumn{2}{c}{ Formation diagonal circulars } \\
\cline { 2 - 3 } Sample & Escherichia coli & Staphylococcus aureus \\
\hline B 1 & $21 \mathrm{~mm}$ & $25 \mathrm{~mm}$ \\
C2 & $18 \mathrm{~mm}$ & $20 \mathrm{~mm}$ \\
C3 & $20 \mathrm{~mm}$ & $24 \mathrm{~mm}$ \\
C4 & $22 \mathrm{~mm}$ & $20 \mathrm{~mm}$ \\
\hline
\end{tabular}



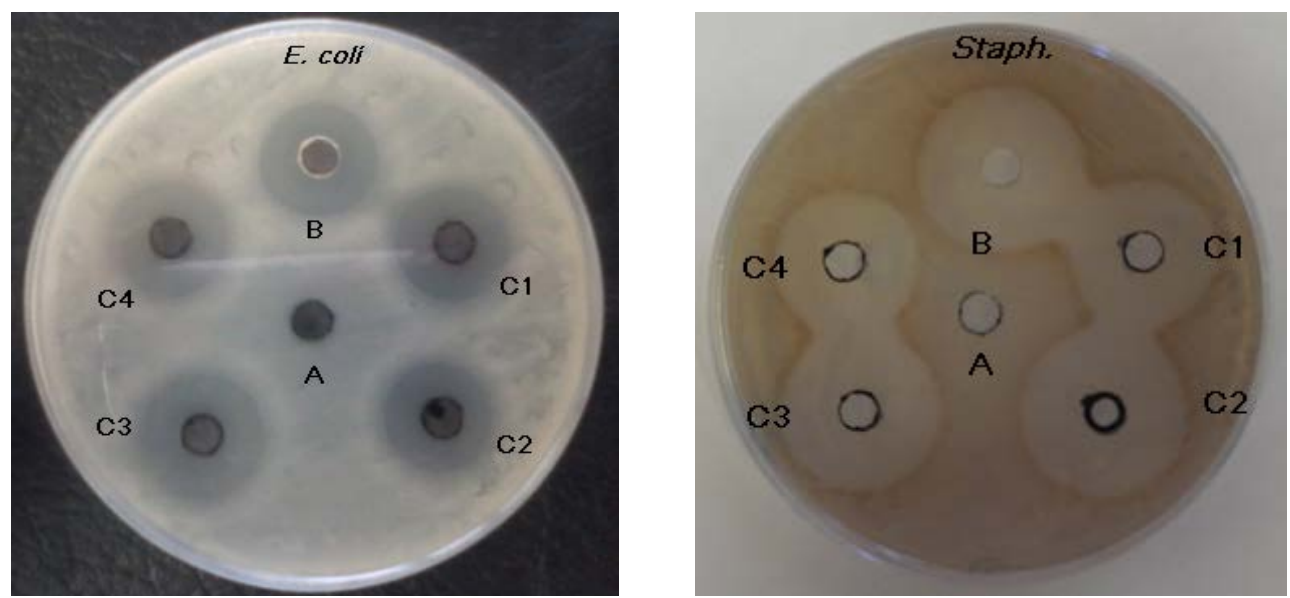

Figure 5. A schematic illustration of created inhibition zones for antibacterial activity of PVA/PANi polymer (A), ZnO NPs (B) and various concentrations of nanocomposites 1\% (C1), 1.5\% (C2), 2\% (C3) and $2.5 \%$ (C4).

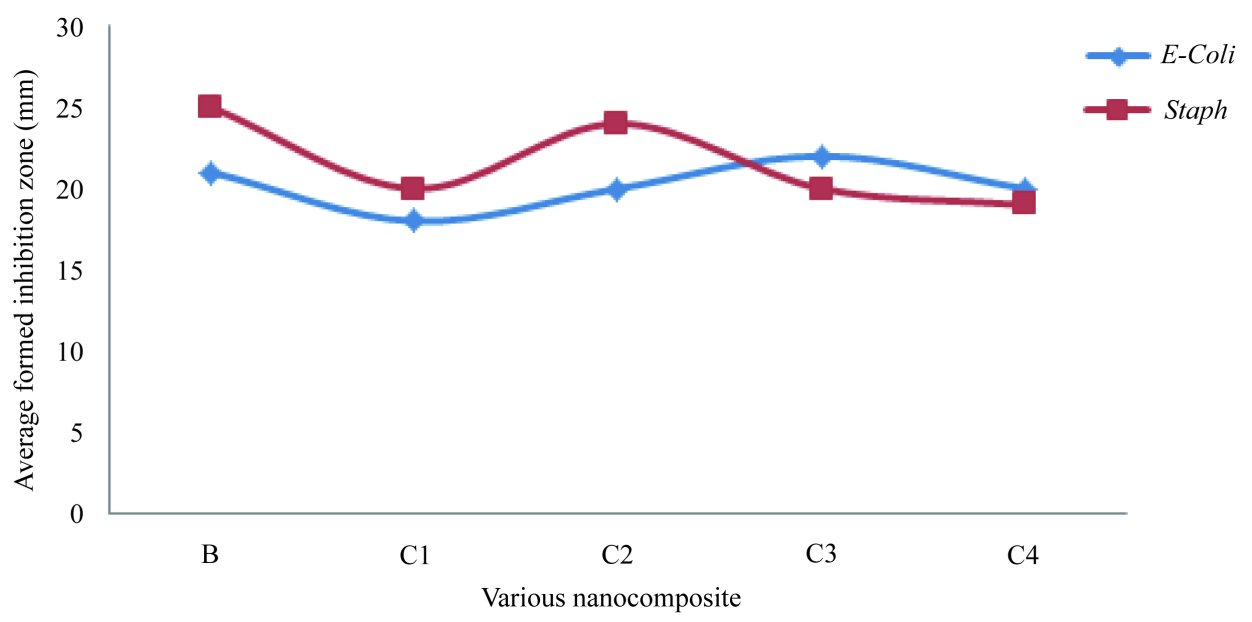

Figure 6. Scatter plot of inhibition zone versus $\mathrm{ZnO}$ NPs and various concentrations of nanocomposites $1 \%(\mathrm{C} 1), 1.5 \%(\mathrm{C} 2), 2 \%(\mathrm{C} 3)$ and $2.5 \%(\mathrm{C} 4)$.

\section{Conclusion}

ZnO NPs were synthesized using $\mathrm{ZnO}$ powder. PVA/PANi/ZnO nanocomposites were prepared in different concentrations of ZnO NPs [1\% (C1), 1.5\% (C2), 2\% (C3) and 2.5\% (C4)]. The antibacterial activity of PVA/ $\mathrm{PANi} / \mathrm{ZnO}$ nanocomposites at different sizes of ZnO NPs was shown a strong antibacterial activity against Gram-positive and Gram-negative bacteria. These results were shown that the antibacterial resistance of $\mathrm{ZnO}$ NPs in nanocomposites could be modified according to their size distribution, and decreased with increasing in particle size. Further studies should be focused on the investigation of cytotoxic effects and the bactericidal effects of PVA/PANi/ZnO nanocomposites against different types of bacteria for potential widening of their applications, such as in surgical devices and in drug-delivery. Moreover, the XRD analysis peaks for ZnO NPs were in good agreement with those of hexagonal wurtzite structure. SEM images were shown an appropriate size distribution of ZnO NPs onto the polymer kip, and smaller sizes for ZnO NPs in lower concentration nanocomposites. The size distribution for different concentrations of nanocomposites was at the range 22.57 - 33.90 nm.

\section{Acknowledgements}

This research has been accomplished under financial support of the Department of Chemistry, University of 
Zabol and cordially laboratorial collaboration of the Faculty of Pharmacy, Zabol University of Medical Sciences, which should be appreciated.

\section{References}

[1] Zhou, B. and Balee, R. (2005) Groenendaal, Nanoparticle and Nanostructure Catalysts: Technologies and Markets. Nanotech. Law Business, 2, 222.

[2] Peukert, W., Schwarzer, H.C., Gotzinger, M., Gunther, L. and Stenger, F. (2003) Control of Particle Interfaces-The Critical Issue in Nanoparticle Technology. Advanced Powder Technology, 14, 411-426. http://dx.doi.org/10.1163/156855203769710645

[3] Sun, C., Lee, J.S. and Zhang, M. (2008) Magnetic Nanoparticles in MR Imaging and Drug Delivery. Advanced Drug Delivery Reviews, 60, 1252-1265. http://dx.doi.org/10.1016/j.addr.2008.03.018

[4] Ko, S.H., Park, I., Pan, H., Grigoropoulos, C.P., Pisano, A.P., Luscombe, C.K. and Fréchet, J.M. (2007) Direct Nanoimprinting of Metal Nanoparticles for Nanoscale Electronics Fabrication. Nano Letters, 7, 1869-1877. http://dx.doi.org/10.1021/nl070333v

[5] Patil, S., Shinde, S. and Rajpure, K. (2013) Physical Properties of Spray Deposited Ni-Doped Zinc Oxide Thin Films. Ceramics International, 39, 3901-3907. http://dx.doi.org/10.1016/j.ceramint.2012.10.234

[6] Labuayai, S., Promarak, V. and Maensiri, S. (2009) Synthesis and Optical Properties of Nanocrystalline ZnO Powders Prepared by a Direct Thermal Decomposition Route. Applied Physics A, 94, 755-761. http://dx.doi.org/10.1007/s00339-008-4984-2

[7] Suwanboon, S., Amornpitoksuk, P., Bangrak, P. and Randorn, C. (2014) Physical and Chemical Properties of Multifunctional ZnO Nanostructures Prepared by Precipitation and Hydrothermal Methods. Ceramics International, 40, 975983. http://dx.doi.org/10.1016/j.ceramint.2013.06.094

[8] Yılmaz, S., Nisar, J., Atasoy, Y., McGlynn, E., Ahuja, R., Parlak, M. and Bacaksız, E. (2013) Defect-Induced Room Temperature Ferromagnetism in B-Doped ZnO. Ceramics International, 39, 4609-4617. http://dx.doi.org/10.1016/j.ceramint.2012.11.060

[9] Suwanboon, S., Amornpitoksuk, P., Sukolrat, A. and Muensit, N. (2013) Optical and Photocatalytic Properties of LaDoped ZnO Nanoparticles Prepared via Precipitation and Mechanical Milling Method. Ceramics International, 39, 2811-2819. http://dx.doi.org/10.1016/j.ceramint.2012.09.050

[10] Yu, A., Qian, J., Pan, H., Cui, Y., Xu, M., Tu, L., Chai, Q. and Zhou, X. (2011) Micro-Lotus Constructed by Fe-Doped ZnO Hierarchically Porous Nanosheets: Preparation, Characterization and Gas Sensing Property. Sensors and Actuators B: Chemical, 158, 9-16. http://dx.doi.org/10.1016/j.snb.2011.03.052

[11] Zhang, C. (2007) The Influence of Post-Growth Annealing on Optical and Electrical Properties of P-Type ZnO Films. Materials Science in Semiconductor Processing, 10, 215-221. http://dx.doi.org/10.1016/j.mssp.2008.01.001

[12] Seo, M., Jung, Y., Lim, D., Cho, D. and Jeong, Y. (2013) Piezoelectric and Field Emitted Properties of Controlled ZnO Nanorods on CNT Yarns. Materials Letters, 92, 177-180. http://dx.doi.org/10.1016/j.matlet.2012.10.076

[13] Li, R., Yabe, S., Yamashita, M., Momose, S., Yoshida, S., Yin, S. and Sato, T. (2002) Synthesis and UV-Shielding Properties of $\mathrm{ZnO}$ - and $\mathrm{CaO}-$ Doped $\mathrm{CeO}_{2}$ via Soft Solution Chemical Process. Solid State Ionics, 151, 235-241. http://dx.doi.org/10.1016/S0167-2738(02)00715-4

[14] Qin, L., Shing, C., Sawyer, S. and Dutta, P.S. (2011) Enhanced Ultraviolet Sensitivity of Zinc Oxide Nanoparticle Photoconductors by Surface Passivation. Optical Materials, 33, 359-362. http://dx.doi.org/10.1016/j.optmat.2010.09.020

[15] Mousa, M., Bayoumy, W. and Khairy, M. (2013) Characterization and Photo-Chemical Applications of Nano-ZnO Prepared by Wet Chemical and Thermal Decomposition Methods. Materials Research Bulletin, 48, 4576-4582. http://dx.doi.org/10.1016/j.materresbull.2013.07.050

[16] Talebian, N., Amininezhad, S.M. and Doudi, M. (2013) Controllable Synthesis of ZnO Nanoparticles and Their Morphology-Dependent Antibacterial and Optical Properties. Journal of Photochemistry and Photobiology B: Biology, 120, 66-73. http://dx.doi.org/10.1016/j.jphotobiol.2013.01.004

[17] Lee, S.D., Nam, S.H., Kim, M.H. and Boo, J.H. (2012) Synthesis and Photocatalytic Property of ZnO Nanoparticles Prepared by Spray-Pyrolysis Method. Physics Procedia, 32, 320-326. http://dx.doi.org/10.1016/j.phpro.2012.03.563

[18] Sharma, D., Sharma, S., Kaith, B., Rajput, J. and Kaur, M. (2011) Synthesis of ZnO Nanoparticles Using Surfactant Free In-Air and Microwave Method. Applied Surface Science, 257, 9661-9672. http://dx.doi.org/10.1016/j.apsusc.2011.06.094

[19] Kazeminezhad, I., Sadollahkhani, A. and Farbod, M. (2013) Synthesis of ZnO Nanoparticles and Flower-Like Nanostructures Using Nonsono- and Sono-Electrooxidation Methods. Materials Letters, 92, 29-32. 
http://dx.doi.org/10.1016/j.matlet.2012.10.064

[20] Ba-Abbad, M.M., Kadhum, A.A.H., Bakar Mohamad, A., Takriff, M.S. and Sopian, K. (2013) The Effect of Process Parameters on the Size of ZnO Nanoparticles Synthesized via the Sol-Gel Technique. Journal of Alloys and Compounds, 550, 63-70. http://dx.doi.org/10.1016/j.jallcom.2012.09.076

[21] Aneesh, P.M., Vanaja, K.A. and Jayaraj, M.K. (2007) Synthesis of ZnO Nanoparticles by Hydrothermal Method. Proceedings of SPIE, 6639, 66390J-1-66390J-9.

[22] Stanković, A., Veselinović, L., Škapin, S., Marković, S. and Uskoković, D. (2011) Controlled Mechanochemically Assisted Synthesis of ZnO Nanopowders in the Presence of Oxalic Acid. Journal of Materials Science, 46, 3716-3724. http://dx.doi.org/10.1007/s10853-011-5273-6

[23] Sawai, J., Igarashi, H., Hashimoto, A., Kokugan, T. and Shimizu, M. (1995) Evaluation of Growth Inhibitory Effect of Ceramics Powder Slurry on Bacteria by Conductance Method. Journal of Chemical Engineering of Japan, 28, 288293. http://dx.doi.org/10.1252/jcej.28.288

[24] Tankhiwale, R. and Bajpai, S. (2012) Preparation, Characterization and Antibacterial Applications of ZnO-Nanoparticles Coated Polyethylene Films for Food Packaging. Colloids and Surfaces B: Biointerfaces, 90, 16-20. http://dx.doi.org/10.1016/j.colsurfb.2011.09.031

[25] Sharma, D., Rajput, J., Kaith, B., Kaur, M. and Sharma, S. (2010) Synthesis of ZnO Nanoparticles and Study of Their Antibacterial and Antifungal Properties. Thin Solid Films, 519, 1224-1229. http://dx.doi.org/10.1016/j.tsf.2010.08.073

[26] Tam, K., Djurišić, A., Chan, C., Xi, Y., Tse, C., Leung, Y., Chan, W., Leung, F. and Au, D. (2008) Antibacterial Activity of ZnO Nanorods Prepared by a Hydrothermal Method. Thin Solid Films, 516, 6167-6174. http://dx.doi.org/10.1016/j.tsf.2007.11.081

[27] Wang, H.H., Shyr, T.W. and Hu, M.S. (1999) The Elastic Property of Polyvinyl Alcohol Gel with Boric Acid as a Cross-Linking Agent. Journal of Applied Polymer Science, 74, 3046-3052. http://dx.doi.org/10.1002/(SICI)1097-4628(19991220)74:13<3046::AID-APP6>3.0.CO;2-1

[28] Scotchford, C., Cascone, M., Downes, S. and Giusti, P. (1998) Osteoblast Responses to Collagen-PVA Bioartificial Polymers in Vitro: The Effects of Cross-Linking Method and Collagen Content. Biomaterials, 19, 1-11. http://dx.doi.org/10.1016/S0142-9612(97)00236-6

[29] Chandrakala, H., Ramaraj, B. and Lee, J.H. (2013) Polyvinyl Alcohol/Carbon Coated Zinc Oxide Nanocomposites: Electrical, Optical, Structural and Morphological Characteristics. Journal of Alloys and Compounds, 580, 392-400. http://dx.doi.org/10.1016/j.jallcom.2013.06.091

[30] Hebeish, A., Abdelhady, M. and Youssef, A. (2013) $\mathrm{TiO}_{2}$ Nanowire and $\mathrm{TiO}_{2}$ Nanowire Doped Ag-PVP Nanocomposite for Antimicrobial and Self-Cleaning Cotton Textile. Carbohydrate Polymers, 91, 549-559. http://dx.doi.org/10.1016/j.carbpol.2012.08.068

[31] Shin, J., Kim, Y., Lee, K., Lim, Y.M. and Nho, Y.C. (2008) Significant Effects of Sodium Acetate, an Impurity Present in Poly(vinyl alcohol) Solution on the Radiolytic Formation of Silver Nanoparticle. Radiation Physics and Chemistry, 77, 871-876. http://dx.doi.org/10.1016/j.radphyschem.2007.12.006

[32] Cruz-Silva, R., Ruiz-Flores, C., Arizmendi, L., Romero-Garcia, J., Arias-Marin, E., Moggio, I., Castillon, F. and Farias, M. (2006) Enzymatic Synthesis of Colloidal Polyaniline Particles. Polymer, 47, 1563-1568. http://dx.doi.org/10.1016/j.polymer.2005.12.082

[33] Sarno, D.M., Manohar, S.K. and MacDiarmid, A.G. (2005) Controlled Interconversion of Semiconducting and Metallic Forms of Polyaniline Nanofibers. Synthetic Metals, 148, 237-243. http://dx.doi.org/10.1016/j.synthmet.2004.09.038

[34] Stejskal, J. and Gilbert, R. (2002) Polyaniline. Preparation of a Conducting Polymer (IUPAC Technical Report). Pure and Applied Chemistry, 74, 857-867. http://dx.doi.org/10.1351/pac200274050857

[35] AbdElhady, M. (2012) Preparation and Characterization of Chitosan/Zinc Oxide Nanoparticles for Imparting Antimicrobial and UV Protection to Cotton Fabric. International Journal of Carbohydrate Chemistry, 2012, 1-6.

[36] Bhadra, J. and Sarkar, D. (2010) Size Variation of Polyaniline Nanoparticles Dispersed in Polyvinyl Alcohol Matrix. Bulletin of Materials Science, 33, 519-523. http://dx.doi.org/10.1007/s12034-010-0079-8

[37] Hwang, J.J. and Ma, T.W. (2012) Preparation, Morphology, and Antibacterial Properties of Poly Acrylonitrile/Montmorillonite/Silver Nanocomposites. Materials Chemistry and Physics, 136, 613-623. http://dx.doi.org/10.1016/j.matchemphys.2012.07.034

[38] Maensiri, S., Laokul, P. and Promarak, V. (2006) Synthesis and Optical Properties of Nanocrystalline ZnO Powders by a Simple Method Using Zinc Acetate Dihydrate and Poly(vinyl pyrrolidone). Journal of Crystal Growth, 289, 102-106. http://dx.doi.org/10.1016/j.jcrysgro.2005.10.145

[39] Sankara Reddy, B., Venkatramana Reddy, S., Koteeswara Reddy, N. and Pramoda, K. (2013) Synthesis, Structural, Optical Properties and Antibacterial Activity of Co-Doped (Ag, Co) ZnO Nanoparticles. Research Journal of Material 
Sciences, 1, 11-20.

[40] Guo, M., Diao, P. and Cai, S. (2005) Hydrothermal Growth of Well-Aligned ZnO Nanorod Arrays: Dependence of Morphology and Alignment Ordering upon Preparing Conditions. Journal of Solid State Chemistry, 178, 1864-1873. http://dx.doi.org/10.1016/j.jssc.2005.03.031

[41] Brayner, R., Ferrari-Iliou, R., Brivois, N., Djediat, S., Benedetti, M.F. and Fiévet, F. (2006) Toxicological Impact Studies Based on Escherichia coli Bacteria in Ultrafine ZnO Nanoparticles Colloidal Medium. Nano Letters, 6, 866-870. http://dx.doi.org/10.1021/nl052326h 